All do not think so, for some cup and bleed; but whether with that amount of benefit which will in any way compensate for the great depression of bodily strength which is almost inevitable, and which fully shows itself the moment convalescence begins, I will not determine for them. I am decidedly opposed to it, have never been obliged to resort to it, and cannot bring my mind to see the least reason for it. A man perfectly well, is suddenly seized; has at times excessive pain of head, principally in the forehead and eyes. Certainly there is not inflammation; and what then is this pain but a nervous one, and why for that deplete, when the time will shortly arrive, under the most favorable circumstances, that all of the strength left is required for convalescence, which is the most difficult part of the treatment to manage. With the exception of the recipe alluded to, which is as follows, $\mathbf{I}$ give scarcely anything but cold gum-water, lemonade or flax-seed tea :-R. Nit. potass., $9 \mathrm{ij}$. to $3 \mathrm{j}$. ; chlor. potass., $Э \mathrm{j}$. to $Э \mathrm{ij}$. ; vin antim., 3 ss. to $3 \mathrm{j}$. ; spts. nit. dulc., $\xi$ ss. to $\zeta$ j. ; aq. f. aurant., $\zeta$ j. to $\zeta \mathrm{ij}$; aq. destil., $\zeta$ vj. to $\xi$ viij. Of this the dose is two to four teaspoonsful every hour, and the free use of cold drinks. With the medicines above named, and that is all I can for the life of me see any necessity of giving, all of my patients get well ; the fever goes off in twelve to thirty hours, gradually diminishing after it has once commenced. Under its use I feel sure all will go right, and merely continue it without change. 1 feel disposed to let well enough alone, believing that the human body was made sufficiently perfect to be able to withstand a few days fever. I shall certainly hold on to my present plan, as long as I find no drawback while adopting it.

If, on the 4th, 5th and 6th day, I find my patient free from all disease, indulging in moderation simple fare, and hourly improving, what more can I or they ask or desire? I know of very many melancholy cases where quinine and morphine have apparently done so much more harm than all the good they have done in other cases, that I could not think of using them.

The mail is about closing, or I might extend these remarks, to a certain extent condemning some old-established usages here, which I have done, and thus far always to the benefit of my patients. I forgot to say that cold salt-water injections, three or four tablespoonsful to two quarts, act well; they relieve the head, diminish fever, and clear out or bring down the hepatic secretion.

\title{
CASE OF POPLITEAL ANEURISM.
}

\section{[Communicated for the Boston Medical and Surgical Journa].]}

IN the treatment of the following case I was associated with my friend Dr. S. W. Williams. The patient, a laborer, 60 years of age, had lived an irregular life, yet his constitutional vigor did not appear to be seriously impaired. His account of himself was, that not more than two months since he accidentally discovered a small swelling in the ham, which, however, was considered of no importance, until recently it sud- 
denly, and without assignable cause, became excessively augmented in volume, entirely filling and rising prominently out of the popliteal space. It was so painful that poultices were applied for relief, and in this condition we found hirn.

The aneurismal tumor, for such it was, was surrounded by a tense diffused swelling, extending somewhat up the thigh and downward to the foot, rendering the leg painful, tender, cold and ecchymosed. 'The tumor had a powerful synchronous pulsation, which could be easily arrested by pressure upon the artery at Poupart's ligament. Its volume was thereby diminished, but it returned directly upon relieving the compression. The blowing murmur was distinctly audible, and altogether the pathology of the case and the indication of treatment appearing so obvious, we tied the femoral artery without delay at the upper third of the thigh.

Pulsation never returned in the tumor, which immediately collapsed, and the final result of the operation was entirely successful.

Greenfield, Sept. 6th, 1853.

James Deane.

\section{THE BOSTON MEDICAL AND SURGICAL JOURNAL.}

ROSTON, SEPTEMBER $14,1853$.

Contagiousness of Yellow Fever,-For many years, very little has been said in favor of the opinion, once generally entertained, that the yellow fever could be carried from one place to another, and thus propagated. Physicians at the South have pretty uniformly agreed that the disease was not contagious; but the people generally believe that it is, and municipal health regulations, throughout the United States, are enforced upon the principle that if all communication with the sick is cut off, the malady may possibly be controlled. It is quite remarkable, and will be so regarded by our suc. cessors, that while learned medical writers and public medical advisers stand firmly in the doctrine of non-contagion in this matter, every board of health acts independently of their advice, and often contrary to their counsel. The legislatures of the different States, and even the general government, also pursue the same course. Under ordinary circumstances, this would be called a gross insult; but the wise ones swallow all with a pacific deportment-still insisting that no danger is to be apprehended from yellow fever. Evidence of a conclusive character seems to have been presented in New Orleans, to show that the present scourge was introduced by a vessel; and in every previous instance, when the fever has swept off the citizens by thonsands, the infliction, us it has appeared afterwards, might have been avoided by a strict health police examination. At Natchez, the fact is undeniable that the yellow fever was carried there from the infected city below; and thus it creeps onward, sweeping away, as it moves, masses of human beings, whose lives might have been preserved by ordinary vigilance and non-intercourse. Individually, we are obliged to believe in the infectious character of this southern plague. If the medical authorities, numerous and respectable as they are, still adhere to their medical conclusions, we are compelled to acknowledge that the history of these epidemics is against them; the popular sentiment declares they are in an error; and those who 